\title{
Comunidade de prática (COP) e aprendizagem organizacional no contexto da gestão de pessoas na Universidade Federal da Paraíba (UFPB)
}

\author{
Ilka Maria Soares Campos \\ Jose Washington de Morais Medeiros \\ Marcia Sandra Meireles de Melo
}

\author{
Mestre. Universidade Federal da Paraiba (UFPB) - Brasil. ik.campos@uol.com.br \\ Doutor. Universidade Federal da Parába (UFBP) - Brasil. washi_med@yahoo.com.br \\ Mestre. Universidade Federal da Parába (UFBP) - Brasil. marciammelo@hotmail.com
}

\section{RESUMO}

No cenário de Século XXI, o fenômeno da aprendizagem torna-se cada vez mais evidente e complexo diante da nova ordem mundial. Na conjuntura socioeconômica e político-cultural global, os espectros da informação, da tecnologia, da aprendizagem e do conhecimento tornam-se as principais nuances das estratégias organizacionais. Nesse sentido, esta pesquisa buscou compreender a inter-relação entre comunidade de práticas (CoP) e aprendizagem organizacional, a partir da percepção de gestores da Universidade Federal da Paraíba (UFPB). Quanto à natureza metodológica, trata-se de uma pesquisa classificada como de campo, de abordagem qualiquantitativa, do tipo exploratório-descritiva, cuja coleta de dados deu-se através de questionário misto (perguntas abertas/fechadas), aplicado a gestores da Pró-reitoria de Gestão de Pessoas da UFPB. Considerando a ocupação de cargos estratégicos na instituição, a pesquisa delimitou como sujeitos os dez gestores que são coordenadores e diretores de gestão de pessoas, por meio da Divisão de Educação e Capacitação Profissional. Os resultados apontaram que, do ponto de vista da gestão, não há apropriação do conceito e assimilação das possibilidades com que comunidades de prática podem dimensionar incisivas e promissoras aprendizagens organizacionais. Desse modo, a pesquisa concluiu que não há articulação direta entre comunidades de práticas e compartilhamento de conhecimentos, na perspectiva da percepção e do planejamento da gestão, o que desarmoniza, desprivilegia e desabona a potencialidade da aprendizagem organizacional sob o prisma da gestão.

Palavras-chave: Comunidade de Prática. Aprendizagem Organizacional. Compartilhamento do conhecimento. Universidade Federal da Paraíba (UFPB).

\section{Community of practice (COP) and organizational learning in the context of the management of people at the Federal University of Paraíba (UFPB)}

\begin{abstract}
In the 21st Century scenario, the phenomenon of learning becomes increasingly evident and complex due to the new world order. In the global socioeconomic and political-cultural conjuncture, the spectra of information, technology, learning and knowledge become the main nuances of organizational strategies. In this sense, this research sought to understand the interrelation between community of practices (CoP) and organizational learning, based on the perception of managers of the Federal University of Paraíba (UFPB). As for the methodological nature, it is a research classified as of field, of qualitativequantitative approach, of exploratory-descriptive type, whose data was collected through a mixed questionnaire (open / closed questions), applied to managers of the Human Resources Management Office of the UFPB. Considering the occupation of strategic positions in the institution, the research delimited as subjects the ten managers who are coordinators and directors of people management, in the Division of Education and Professional Training. The results showed that, from the management point of view, there is no appropriation of the concept and assimilation of the possibilities by means of which communities of practice can seize promising organizational learning. Thus, the research concluded that, from the perspective of management perception and planning, there is no direct articulation between the communities of practices and knowledge sharing, which does not support, does not favor and does not enable the potential of organizational learning from the point of view of management.
\end{abstract}

Keywords: Community of Practice. Organizational Learning. Knowledge Sharing UFPB. 


\section{INTRODUÇÃO}

O desenvolvimento acelerado e a utilização do conhecimento nas organizações resultam em um novo cenário organizacional mais preocupado na qualidade de serviços. Nesse cenário, as organizações procuram analisar seus ambientes, processos para desenvolvimento, adotando, por exemplo, estratégias para a aprendizagem organizacional. Assim, a necessidade de desenvolvimento das organizações decorre do fato de que o mundo está se tornando cada vez mais complexo, dinâmico e mutável, frente às articulações entre os ditames da globalização e 0 avanço científico-tecnológico. Tal realidade afeta diretamente a dinâmica das organizações, tornando-as espaços em que a informação, a tecnologia, o conhecimento e a aprendizagem permeiam as relações internas e externas entre as organizações, a sociedade, e a resultante necessidade de resultados promissores entre qualidade, inovação e produtividade. Desse modo, considerando que a capacidade de se reinventar é indispensável às organizações da contemporaneidade, o conhecimento e o processo de aprendizagem são considerados vantagens competitivas para as organizações que buscam um diferencial. Por isso, a intensidade com que as pessoas e as organizações aprendem torna-se fundamental para a vantagem competitiva e para a eficiência de seus próprios propósitos, no seio dos impactos organizacionais e socioculturais resultantes.

É dessa maneira que, na realidade atual global, o desenvolvimento de etapas, processos e métodos da aprendizagem contínua (formais/informais) tornam-se imprescindíveis às organizações. Por essas vias, percebese que o gerenciamento e o compartilhamento do conhecimento passam a ser, ao mesmo tempo, importantes e difíceis de serem geridos e controlados, o que suscita a reestruturação (implantação/desenvolvimento) de práticas de gestão que têm, na informação e no conhecimento, os pilares do planejamento estratégico das organizações contemporâneas. Nesses termos, o desenvolvimento de práticas efetivas de gestão do conhecimento nas organizações também influencia a sistematização de processos de aprendizagem organizacional.

De acordo com Duarte et al. (2015), as organizações convergem para uma dimensão social do conhecimento, na medida em que seus trabalhos se desenvolvem a partir do compartilhamento do conhecimento, experiências e saberes.

Dessa forma, a Comunidade de Prática (CoP) é um processo espontâneo de agrupamento de sujeitos, cuja interação natural e significativa pode suscitar a confluência de ideias que, intercruzadas, fomentam ap rendizagens e perspectivas criativas. A perspectiva da CoP é uma estratégia natural da interação social e, espontaneamente, com potencial produtivo-inovador no trabalho, cujas organizações, atualmente, estão mapeando para fomentar e fortalecer o aprendizado e o compartilhamento do conhecimento. Trata-se de pessoas que interagem regularmente e compartilham de suas práticas, interesses ou objetivos de trabalho, dimensionando a formação do capital humano a partir de dois princípios: a) transferência do conhecimento (socialização/ reflexão/ absorção/ incorporação etc.); e b) inovação (criação/ reelaboração/ sínteses/ mudanças etc.).

Decorrente disso, Comunidades de Prática podem ser constituídas presencial ou virtualmente. Muitas vezes, não precisam se restringir à comunicação virtual, podendo ser complementadas por encontros e reuniões de seus membros. No contexto da gestão do conhecimento, a cultura favorável ao compartilhamento de experiências, a partir da CoP, pode viabilizar melhores práticas nas organizações, tornando-se atraente à aprendizagem colaborativa. Por esses aspectos, caberia à organização contemporânea incentivar a criação de CoPs, cultivando sua manutenção e buscando, permanentemente, meios para disseminação orgânica de conhecimentos práticos articulados com a política e as estratégias organizacionais.

Antonello e Godoy (2011) salientam a importância da interação entre fatores individuais, pessoais e organizacionais, e o impacto da receptividade do indivíduo em relação à aprendizagem. Nesse sentido, as comunidades de prática virtuais são uma variante deste conceito, formadas por pessoas que atuam em um determinado setor e trabalham em organizações diferentes ou em uma mesma corporação, conectadas pelo ciberespaço.

Por conseguinte, estudos empíricos sobre comunidades de práticas são, atualmente, imprescindíveis ao fortalecimento, à concepção e às práticas estratégicas de gestão da aprendizagem organizacional e/ou gestão do conhecimento. Por isso, esta pesquisa buscou compreen der a inter-relação entre comunidade de práticas (CoP) e aprendizagem organizacional, a partir da percepção de gestores da Universidade Federal da Paraíba (UFPB). A investigação partiu da seguinte questão-problema: como a percepção de gestores sobre comunidade de prática incide na aprendizagem organizacional? 
A pesquisa foi suscitada no contexto do Programa de Pós-graduação em Gestão de Organizações Aprendentes (PPGOA/UFPB), situando o fenômeno no cenário das preocupações e da curiosidade que intermediaram a delimitação do fenômeno relacionado ao campo empírico de suas próprias articulações, ou seja, a própria universidade.

Em termos didáticos, o texto estrutura-se a partir dos fundamentos da comunidade de prática e da aprendizagem organizacional, respaldados pela gestão do conhecimento, como processo sistemático, articulado, apoiado na identificação, na geração e no compartilhamento do conhecimento organizacional e suas articulações na Universidade Federal da Paraíba.

\section{COMUNIDADE DE PRÁTICA}

Em termos gerais, o conhecimento organizacional não faz sentido sem o respaldo de comunidades que o valida, cria e/ou refuta. É na perspectiva do reconhecimento e da validação por pares que o conhecimento ressoa nas comunidades as quais desempenha sentidos.

Nesse aspecto, um dos maiores desafios das grandes organizações está centrado em como melhor utilizar o conhecimento que seus colaboradores, continuamente, geram. Mapear e cultivar comunidades de prática tornouse uma das estratégias mais eficazes para a diretriz dos resultados e do desempenho corporativo na era da informação e do conhecimento.

\subsection{Aspectos conceituais}

Comunidade de Prática pode ser definida como as múltiplas perspectivas e possibilidades com que um grupo de pessoas que interagem regularmente para compartilhar (socializar/refutar/ressignificar) suas práticas, interesses ou objetivos de trabalhos, originalmente discutido pelos teóricos organizacionais Wenger e Lave (1998), ao estudarem como as pessoas aprendem.

As comunidades de prática consistem em pessoas que estão ligadas informalmente, direta e/ou indiretamente por interesse comum no aprendizado e, principalmente, na aplicação prática, pensada sobre a necessidade da (re)condução, da (re)elaboração e da (re)criação, em outros termos, sob as bases "velhos formatos em novas roupagens". Por tal potencial inspirador e (trans)formador, as CoPs mantêm, intrínseco em sua natureza, articulações inovadoras potencialmente distintivas.

Comunidade de Prática (CoP), conforme Zaccarelli e Godoy (2012), implica em engajamento mútuo de pessoas que negociam significados, participação em um empreendimento conjunto, com a negociação definida pelos participantes no processo e o desenvolvimento de um repertório compartilhado que foi produzido e adotado no curso de existência da comunidade, tornando-se parte de sua prática.

Uma comunidade de prática - CoP não é, simplesmente, uma comunidade de interesses. Compreende-se por comunidade de interesses um grupo de pessoas que compartilham algo como, por exemplo, pelo desenvolvimento de uma determinada área de conhecimento. Já a CoP corresponde a uma comunidade de pessoas e nas relações de engajamento intrínseco, que trabalham juntas, conversam entre si; trocam informações e opiniões; e são diretamente retroalimentados pelo entendimento mútuo, como uma questão de rotina.

As Comunidades de Prática costumam ser confundidas com times, redes ou grupos de tarefas. Diferentes desses, as Comunidades de Prática são tipicamente voluntárias, informais; emergem pela própria prática do trabalho, operam para além das hierarquias e dos limites organizacionais tradicionais e raramente são reconhecidas pelas organizações (MCKEEN; SMITH, 2002). Surge independente de um objetivo ou tarefa específica na organização (KIMBLE; HILDRETH, 2004; WENGER, 2010).

\subsection{Estratégias das comunidades de prática}

As comunidades de prática são estratégias para a construção do conhecimento que podem ocorrer naturalmente nas relações sociais nos ambientes de trabalho. Entretanto, as comunidades de práticas precisam ser bem aproveitadas pelas organizações, para se tornarem eficientes no processo de aprendizagens organizacionais e do compartilhamento do conhecimento. Assim, com o avanço e a utilização de tecnologias de 
informação e comunicação cresce a participação através das redes sociais, ampliando a comunicação e criação de grupos e redes de relacionamentos dentro e fora das organizações.

Desta feita, as comunidades de prática desenvolvem-se em torno de assuntos relevantes para seus membros e, consequentemente, suas práticas revelam a visão de seus integrantes sobre o que realmente tem importância para eles. Por essas vias, a CoP se autoevidencia pela inter-relação com que grupos de pessoas, unidas pelo trabalho, objetivos e práticas comuns, naturalmente dialogam, refletem a partir da partilha e do compartilhamento da informação e do conhecimento, no sentido de fazerem melhor juntos o que dificilmente podem fazer sozinhos. Por seu caráter peculiar, a constituição de uma CoP dá-se tão naturalmente que, muitas vezes, nem os próprios sujeitos dão-se conta de sua própria existência e força motriz; outras vezes, o surgimento dá-se por "gestação", ou seja, por uma motivação que pode fazer vingar ou não sua efetivação. A partir desse ponto, pode-se destacar que as características mais importantes das comunidades de prática são a sua habilidade e o seu poder de aprender, construir e reconstruir conhecimentos práticos. Com o desenvolvimento científicotecnológico, as estratégias de constituição das CoP emergem com maior proporção, haja vista que o ciberespaço hiperdimensiona a interação e as múltiplas formas com que a comunicação se estrutura, cuja elaboração e readequação de registros ficam documentados, marcando as açães de uma CoP a partir de seus próprios "rastros". O que Lévy (2011) define de ciberespaço é um espaço de comunicação aberta pela interconexão mundial de computadores. Ele ainda explica que a comunicação via Internet e as comunidades virtuais são uma forma de comunicação de "muitos para muitos", defendendo a ideia de que esse espaço virtual, chamado de ciberespaço, cria uma forma nova de comunicação. Assim, as CoPs surgidas no ciberespaço, podem emergir como uma comunidade virtual, cuja colaboração fomenta aprendizagens organizacionais por meio da socialização e da reflexão sobre conhecimentos práticos, relacionados às atividades laborais que envolvem os integrantes.

Nesse contexto, surge a ideia de aprendizagem colaborativa, que tem nas comunidades virtuais sua forma precípua de materialização, concretizando a ideia de criação e compartilhamento do conhecimento.

Palloff e Prati (2002) listam pressupostos que caracterizam as comunidades virtuais como espaço de aprendizagem: a) igualdade no direito de participação entre todos os usuários; b) interação constante; c) foco em interesses comuns; d) trabalho em equipe; e) definição de regras para a participação na própria comunidade. Em todas essas estratégias encontram-se o caráter social e comunitário da aprendizagem, e os diferentes contextos de socialização, como geradores da aprendizagem, ou seja, a comunicação compartilhada ou produzida em equipe. Assim, as pessoas interagem umas com as outras, formando grupos presenciais e/ou virtuais cada vez mais comunicativos, cuja interação reflexiva processa aprendizagens promissoras para as pessoas e as organizações.

\subsection{Aprendizagem organizacional}

Em termos estratégicos, a aprendizagem desempenha um papel relevante na capacidade dinâmicoorganizacional. Na fase contemporânea da modernidade, o aumento da capacidade competitiva, em um mercado global exigente, talvez seja um dos motivos que fazem com que a aprendizagem organizacional seja uma grande necessidade.

No cenário da sociedade em rede, o contexto atual de mudanças organizacionais profundas exige mudanças das pessoas (SENGE, 2017), exigindo competências, habilidades e atitudes condizentes com as complexidades com as quais a cultura digital, a globalização e a competitividade ensejam as possibilidades de aprendizagem para o que Delors (2010) chamou dos quatro pilares da educação do Século XXI: "aprender a aprender", "aprender a fazer", "aprender a ser", "aprender a viver juntos".

Nessa esteira, pode-se dizer que, por isso, a aprendizagem organizacional tem sido concebida, mais recentemente, como a busca para manter e desenvolver a competitividade, a produtividade e a inovação. Para Caldeira e Godoy (2011, p. 6), "o processo de aprendizagem, por sua vez, pode ser facilitado, ao se proporcionar um ambiente favorável ao seu desenvolvimento na organização, ou prejudicado, quando há barreiras à aprendizagem".

Ainda para Antonello e Godoy (2011, p. 79),

A aprendizagem organizacional é utilizada como tecnologia de gestão que amplia o controle das organizações entre os indivíduos, no que se refere ao controle de suas premissas cognitivas, 
não obstante ela esteja fortemente revestida, nos meios acadêmicos e empresariais, por um discurso de autonomia de trabalho e do crescimento do indivíduo.

Nesse sentido, a aprendizagem organizacional é o processo contínuo das pessoas nas organizações em criar, adquirir e socializar conteúdos significativos (conhecimento), através de processos educativos formais, não formais ou informais, incidindo no comportamento das pessoas e na cultura organizacional.

Portanto, a aprendizagem organizacional mostra-se como uma das alternativas viáveis diante das muitas estratégias necessárias para uma gestão voltada para qualidade de serviços. Senge $(2017$, p. 37) define a organização que aprende como:

[...] organizações nas quais as pessoas expandem continuamente sua capacidade de criar os resultados que realmente desejam, onde se estimulam padrões de pensamentos novos e abrangentes, e aspiração coletiva ganha liberdade e onde as pessoas aprendem continuamente a aprender juntas.

Sendo assim, a organização que aprende só consegue constituir-se enquanto tal porque é o sujeito que faz parte seus processos que se põe em condição de aprendizagem, ou seja, como aprendente. Organizações que ensinam a aprender e que têm pessoas que aprendem a aprender compõem um cenário atual para a compreensão da realidade sociocultural e político-econômica em que os processos de trabalho interpelam pessoas e organização a se reconfigurarem, sobretudo a partir de um dos princípios instauradores da aprendizagem e do conhecimento organizacional: o compartilhamento.

\subsection{0 compartilhamento do conhecimento nas organizações}

O conhecimento vem se consolidando como o principal ativo estratégico nas organizações, e o seu papel no processo de criação e compartilhamento é promover o contexto apropriado para facilitar o trabalho colaborativo.

Nonaka e Takeuchi (2008) reforçam que a criação do conhecimento organizacional é uma interação contínua e dinâmica entre o conhecimento tácito e o conhecimento explícito. 0 conhecimento tácito é pessoal, e constitui a base da criação do conhecimento organizacional; já o conhecimento explícito é formal e sistemático, e pode ser facilmente compartilhado.

Corroborando com a discussão sobre conversão, Silva et al. (2014, p.155) afirmam que,

para converter o conhecimento tácito em conhecimento explícito e, a partir daí poder criar inovações, os indivíduos devem ser estimulados, estar motivados e incentivados a participarem continuamente dos processos importantes de suas atividades executadas, e principalmente, a compartilharem seus conhecimentos tácitos, na forma de experiências vividas no ambiente organizacional.

Nesse sentido, é importante que o conhecimento pessoal possa ser transformado em conhecimento organizacional para que a empresa acelere seu aprendizado, crie inovações e amplie seus horizontes.

De acordo com o entendimento de Senge (2017, p. 37),

à medida que o mundo se torna cada vez mais interligado e conectado as empresas são mais complexas e dinâmicas, portanto 0 trabalho deve se tornar mais fácil de aprender. [...] não basta mais ter uma única pessoa aprendendo pela empresa, portanto, as organizações que realmente terão sucesso no futuro serão aquelas que descobrirem como cultivar nas pessoas 0 comprometimento e a capacidade de aprender em todos os níveis da organização.

Diante desse cenário, faz-se necessário compreender que, enquanto ativo intangível, o conhecimento é um dos provedores e promissores recursos que mais agrega valor, qualidade e lucratividade às organizações contemporâneas, pois seu domínio passa a ser o vetor imprescindível para o desenvolvimento de pessoas na organização, e, por isso, passa a ser também o fator fundamental à eficácia da gestão e seus resultados.

É nesse ínterim que o conhecimento tácito, relacionado ao desenvolvimento de pessoas, expõe-se através da necessidade de sua própria manifestação: o compartilhamento. Considerando compartilhar como 
"fazer junto", as pessoas, através de seu conhecimento tácito, tendem a fomentar processos de compartilhamento que, conjuntamente, corroboram com os processos atuais e reais da sociedade em rede, demandando o surgimento das comunidades de prática.

Tal possibilidade arvora-se nas singulares condições com que a aprendizagem vai se constituindo como fenômeno orgânico para o sujeito e para a organização nos processos de trabalho, cuja proeza vai se naturalizando pelas tessituras que engrenam a informação, a aprendizagem, o conhecimento, 0 compartilhamento e o trabalho: faces de uma mesma realidade nas organizações, favorecendo o surgimento das CoP.

\section{TRAÇANDO OS CAMINHOS DA PESQUISA}

Em termos metodológicos, a pesquisa classificou-se como de campo, cuja perspectiva de investigação refere-se a uma coleta dados, in loco, em uma determinada realidade, reunindo informações referentes ao cenário em que os fatos acontecem. Nesse contexto, a pesquisa foi realizada junto aos gestores da Pró-Reitoria de Gestão de Pessoas da UFPB.

Considerando tal aspecto, a investigação fundou-se nas especificidades da abordagem qualitativa. Segundo os preceitos de Richardson (2014) a abordagem qualitativa caracteriza-se pela compreensão dos fenômenos, através da busca de sentidos e significados das coisas no mundo, desvelando os "porquês". Tomando por base tal aspecto, a pretensão foi entender a natureza do fenômeno comunidade de prática como fenômeno social.

Em complementação, do ponto de vista dos objetivos, a pesquisa caracterizou-se como exploratória, pois proporcionou maior familiaridade com o tema, no âmbito institucional; e descritiva porque utilizou da descrição sobre as características do fenômeno (GIL, 2016), valendo-se de uma narrativa condizente e pertinente para a compreensão dos fatos. Rodrigues (2007) enfatiza que a pesquisa descritiva, ao contrário do que muitos outros autores defendem, também pode fazer parte de pesquisas fundamentadas na abordagem qualitativa. Nesse sentido, de acordo com Rodrigues (2007, p. 29) a pesquisa descritiva "poderá recorrer à estatística descritiva, sem deixar de configurar uma pesquisa qualitativa por fazer uso de dados numéricos [...]". Por essa explicação, o autor diz que o discurso descritivo é pictórico, ou seja, utiliza de uma linguagem didaticamente explicativa que propicia 0 entendimento dos fatos de maneira clara, objetiva e precisa.

Desta feita, considerando a pertinência da reunião dos dados, o instrumento utilizado para coleta de dados foi um questionário, composto de perguntas abertas e fechadas (combinado) relacionadas com a fundamentação teórica. Assim, buscou responder as perguntas: Você já ouviu falar em comunidades de prática? Como você definiria comunidades de prática? Você identifica a existência de algum tipo de comunidade prática no seu setor de trabalho? Se sim, como você poderia descrevê-la?

A aplicação do instrumento de coleta de dados foi por meio de correio eletrônico, cujas perguntas visavam responder ao objetivo proposto, concernente a compreender a inter-relação entre comunidade de práticas (COP) e aprendizagem organizacional, a partir da percepção de gestores da Universidade Federal da Paraíba (UFPB). Considerando o viés da gestão organizacional da universidade na Pró-Reitoria de Gestão de Pessoas (PROGEP), o foco da pesquisa centrou-se no universo de 19 gestores que compõem as diretorias e assessorias das divisões desta Pró-Reito ria. Deste escopo, a pesquisa delimitou apenas 11 gestores que formam as diretorias. Tal escolha referiu-se ao fato de que este segmento institucional é o responsável direto pela execução das políticas de capacitação/educação continuada da UFPB, e que, via de regra, está mais diretamente envolvido com o fenômeno da aprendizagem organizacional como meta e como estratégia de gestão, diante dos resultados institucionais perseguidos.

No período estabelecido para a coleta de dados, foram enviados 11 questionários, por e-mail, aos gestores supra, sendo que 10 responderam à pesquisa, o que culminaram em resultados consideráveis para a análise e para a tomada de decisão consequente por parte da instituição.

\section{COMUNIDADES DE PRÁTICA E APRENDIZAGEM ORGANIZACIONAL SOB O PRISMA DE GESTORES}

Os resultados da pesquisa, subsidiados pela análise e interpretação dos dados, estruturaram-se a partir de dois conjuntos textuais: a) perfil do gestor; e b) processos de Gestão do Conhecimento. 


\subsection{Perfil do gestor}

A "faixa etária" dos gestores pesquisados tem em sua maioria idades entre 31 a 40 anos e 1 (um) acima de 50 anos, o que apresenta um quadro relativamente jovem de gestores. Entretanto, cabe destacar a presença feminina com 5 participantes, o que representa a metade do total dos integrantes na função de chefia. Nesse contexto, sabe-se que, atualmente, as instituições possuem significativa parcela feminina que integra seus quadros funcionais. A situação apresentada pode ser indício de que a mulher demonstre identificação e propensão para assumir e liderar a condução gerencial, principalmente, de atividades relacionadas à área de gestão de pessoas, na PROGEP/UFPB. Logo, essa representação feminina demonstra, talvez, que isso se dá pelo seu grande grau de sensibilidade, amabilidade com seus pares, como também pela habilidade em estimular a participação coletiva.

Na formação acadêmica, constatou-se que os gestores na sua maioria possuem Especialização e Mestrado, o que demonstra o engajamento dos sujeitos para com sua qualificação profissional e/ou formação continuada. Quanto ao tempo na instituição, os gestores que ocupam cargos de coordenações e/ou direções da Pró-Reitoria de Gestão de Pessoas (PROGEP), constatou-se, com a pesquisa, que o tempo que estes têm na UFPB é relativamente curto, já que em sua maioria (6) possuem menos de 5 anos. Logo, observa-se que mesmo não tendo tanto tempo na instituição, menos de 03 anos em sua maioria, já estão ocupando funções de chefia. Percebeu-se ainda que este perfil pode apresentar novas aberturas para inovação organizacional. De acordo com Nonaka e Takeuchi (2008), o novo paradigma organizacional enfatiza o conhecimento e a criatividade. Nesse sentido, as atividades de gestão e liderança nas organizações podem ser aprimoradas mediante as necessidades de cada momento e do contexto organizacional, o que significa dizer que, hoje, o valor de uma instituição não está na sua estrutura física, nos equipamentos tecnológicos, mas sim pela capacidade intelectual das pessoas que nela atuam.

\subsection{Processos de compartilhamento do conhecimento}

Buscando identificar a percepção dos gestores da PROGEP quanto à existência de indícios de práticas atribuídas aos processos de aprendizagem organizacional e compartilhamento do conhecimento, o primeiro aspecto de investigação correspondeu às formas de reuniões, como possibilidade de comunidade de prática. De acordo com Wenger, McDermott e Snyder (2002), uma comunidade de prática se distingue de uma comunidade de interesses ou uma comunidade geograficamente situada, na medida em que a mesma envolve 0 compartilhamento de práticas que detêm um foco em comum. Esse compartilhamento de práticas é considerado como o domínio da comunidade de prática, sendo o primeiro aspecto distintivo.

Os respondentes, quando indagados sobre as formas de reuniões, todos os 10, evidenciaram que as reuniões parecem ser infrutíferas, e, talvez, seja importante estabelecer critérios diferentes que possam promover intervenção nas reuniões; como também adotar critérios que favoreçam uma melhor interação entre os gestores e uma constância das reuniões. Nesse ínterim, para Antonello e Godoy (2011, p. 119) "as interações ocorrerem nos grupos de maneira mais frequente, com compartilhamento de interesses e práticas de modo informal".

Outro aspecto característico à área de gestão de pessoas é a motivação entre os gestores, sobretudo para discutirem tomadas de decisões. Constatou-se um fenômeno inverso, uma vez que as decisões tomadas em reuniões, como evidenciaram os respondentes, não fomentam mudanças para melhorias nos processos e ambientes de trabalho.

Pelos resultados apresentados, podemos afirmar que existe uma predominância entre os gestores em concordarem "parcialmente" com esses aspectos, sendo que um dos gestores (R04) foi categórico em dizer que não se sente "motivado para participar das reuniões", e que essas discussões "não agregam valor para as tomadas de decisões, parcialmente mudam comportamentos laborais".

A correlação dos recursos tecnológicos na aprendizagem organizacional, e a utilização das redes sociais para questões de trabalho foram enfatizados, e os gestores demonstraram opiniões convergentes, ou seja, de modo geral, foi dito que, se as reuniões forem utilizadas de modo adequado, darão celeridade aos processos de trabalho e, consequentemente, contribuírão para uma melhor organização das informações e compartilhamento do conhecimento. 
Os dados coletados revelam que todos se utilizam de algum recurso tecnológico, relacionado às mídias digitais e/ou redes sociais, principalmente o WhatSapp, para facilitar a disseminação das informações, opiniões e sugestões relevantes à equipe de trabalho, pois se trata de uma ferramenta acessível, instantânea e eficaz.

Para Nonaka e Takeuchi (2008), a organização não é simplesmente uma máquina de processamento de informação, mas uma entidade que cria conhecimento através da ação e da interação. Os autores destacam a importância da percepção do uso dos recursos tecnológicos como um fato que representa uma alternativa real para ampliar os espaços de interação, de troca de informações de compartilhamento de conhecimento, em uma série de ações que fixa interesses gerais para além de interesses particulares. 0 que está em jogo nesse processo é a existência de comunidades de prática, na medida em que estas se estabelecem pela ação dos princípios de interação, cujo espírito se desdobra e transforma em experiência.

Quando indagados sobre o conhecimento do termo "comunidades de prática", identificou-se uma predominância de consenso em relação à questão suscitada, conforme o Quadro 1, haja vista que apenas 2 afirmaram nunca ter ouvido falar no assunto. Com intuito de preservação da identificação dos gestores será utilizado como identificação a letra " $R$ " para cada um dos respondentes.

\section{Quadro 1 - Concepção dos gestores sobre CoP}

\begin{tabular}{|c|l|}
\hline $\begin{array}{c}\text { GESTOR/ } \\
\text { RESPONDENTE }\end{array}$ & \multicolumn{1}{c|}{ CONCEPÇÃO SOBRE CoP } \\
\hline $\mathbf{R 1}$ & $\begin{array}{l}\text { "[...] comunidade de Prática poderia ser caracterizada como um grupo de pessoas que } \\
\text { interagem em torno de um interesse comum. Buscam meios de melhorar o que } \\
\text { desenvolvem visando a resolução de problemas laborais no aprendizado coletivo". }\end{array}$ \\
\hline R2 & $\begin{array}{l}\text { "[...] o termo "comunidade de prática" é relativamente novo para mim, no entanto, } \\
\text { acredito que a prática desse tipo de ação já seja recorrente no ambiente de trabalho } \\
\text { no qual estou inserida. Para mim comunidades de prática são ações formais ou } \\
\text { informais que viabilizam a troca de informações, sugestões, opiniões entre os } \\
\text { indivíduos que compõem as equipes de trabalho. Buscando organização e melhorias } \\
\text { para a equipe assim como para os processos desenvolvidos". }\end{array}$ \\
\hline R3 & $\begin{array}{l}\text { "[...] um conjunto de pessoas, com diferentes formações que se reúnem para discutir } \\
\text { um tema ou construir alguma coisa." }\end{array}$ \\
\hline R4 & $\begin{array}{l}\text { "[...] um conjunto de pessoas que possuem um interesse em comum ou uma prática } \\
\text { em comum e devido a isso estabelecem inúmeras comunicações virtuais ou } \\
\text { presenciais para discutir e aprimorar o entendimento e forma de realização desta } \\
\text { prática ou interesse." }\end{array}$ \\
\hline R5 & $\begin{array}{l}\text { "[...] talvez seja um grupo de pessoas que discutem práticas de trabalho, talvez seja } \\
\text { isso." }\end{array}$ \\
\hline R6 & $\begin{array}{l}\text { "[...] imagino que seja um fórum uma comunidade de gestores que operam e } \\
\text { trabalham com as mesmas demandas." }\end{array}$ \\
\hline R7 & "[...]na gestão deve ser o que é praticado e o que deve ser praticado." \\
\hline R8 & "[...] pessoas que se reúnem e trocam experiências, práticas." \\
\hline R9 & "[...] não sei o que é isso não. O que é isso, hein?" \\
\hline "[...] nunca ouvir falar, não, de Comunidades de Prática."
\end{tabular}

Fonte: Dados da pesquisa (2017).

Quando os gestores falam em Comunidades de Prática estão dando uma noção empírica em termos de significado. Percebe-se, pelas falas, o entendimento dos gestores em relação à estrutura de fomento à aprendizagem organizacional e de geração do conhecimento. Wenger (2010), sobre comunidades de prática, diz que estas não são apenas um agregado de pessoas que possuem algumas características comuns, mas, sim, pessoas que, por meio da interação e convivência, aprendem e criam juntas, podendo gerar diferencial e, até vantagens competitivas diante das promessas de inovação que podem surgir diante de conhecimentos práticos intermediados pelos sujeitos. 
Nesse contexto, é interessante destacar que se trata de uma comunidade de pessoas que compartilham formas de trabalho, experiências, instrumentos e práticas, e que as comunidades de prática desenvolvem assuntos relevantes para seus membros, podendo ir além dos limites tradicionais dos grupos ou equipes de trabalho, já que surgem de forma espontânea, sob o princípio da adesão voluntária e natural.

Indagados sobre a existência de algum tipo de comunidade prática no seu setor de trabalho, nove gestores expressaram a mesma percepção sobre a questão, acreditando que reuniões informais e as trocas de mensagens realizadas no "Spark" (aplicativo de comunicação institucional - troca de mensagens) ou nos grupos de whatsapp podem ser consideradas como comunidades de práticas, posto que ajudam aos gestores a buscar um ambiente propicio à integração e à troca de informações na instituição. Os resultados mostram que, para os sujeitos da pesquisa, Comunidades de Prática costumam ser confundidas com times, redes ou grupos de tarefas.

Algumas organizações assumem outras nomenclaturas para as CoPs, tais como redes de aprendizagem, grupos temáticos, clubes de tecnologia, dentre outras. As CoPs podem ser grandes ou pequenas, presenciais ou virtuais, locais ou globais, com membros internos ou externos à organização (FERNANDES; CAPAVERDE; SILVA, 2016, p. 4).

É importante destacar que as comunidades de prática, muitas vezes, não se restringem à comunicação virtual, mas por pessoas que estejam reunidas, de alguma forma, pelos mesmos interesses e pelos mesmos problemas. Só a utilização dessas ferramentas como Spark, WhatSapp não garantem a existência de uma comunidade de prática. Segundo Wenger (2010), é preciso o compartilhamento de interesses, um conjunto de problemas comuns, uma paixão e respeito à temática, além do aprofundamento do conhecimento e da experiência nesta área por meio de interações contínuas.

Esse processo de interações contínuas, certamente, contribuirá para que comunidades de prática definam de modo mais claro as suas vocações profissionais e perfis institucionais, o que as conduzirá, ao mesmo tempo, a intensificarem a busca de resultados satisfatórios e adequados aos objetivos por elas proclamados.

\section{CONSIDERAÇÕES FINAIS}

Nesta pesquisa, refletiu-se sobre os indícios e condições ao surgimento de comunidades de prática. Para tanto, buscou-se a literatura pesquisada, relacionada à aprendizagem organizacional.

Por meio das evidências da pesquisa, constatou-se que, apesar de promoverem substantiva aprendizagem organizacional, as comunidades de prática são quase inexistentes e/ou pouco expressivas na PROGEP/UFPB, no ponto de vista da gestão. Isso permite perceber que há elementos que funcionam como inibidores de condições fecundas ao desenvolvimento de comunidades de prática, cujas bases estão ou na falta de estratégias dos gestores em rastrear melhor as possibilidades expressivas de comunidades de práticas existentes na PROGEP/UFPB ou falta de condições que fazem esvanecer o fortalecimento de comunidades de prática que mostram sinais de visibilidade.

Nesse sentido, os resultados obtidos apontaram para o fato de que não há uma apropriação e assimilação dos preceitos pragmáticos e estratégicos de comunidades de prática, em termos de sua motivação na realidade no ambiente de trabalho, já que as reuniões, em sua maioria, não tiveram a conotação de trocar experiências, ideias, sugestões para agregar valor de qualidade, mas basicamente de comunicar alguns assuntos e de determinar o que deveria ser feito. Assim, percebeu-se com a pesquisa que não existem comunidades de práticas e compartilhamento de conhecimentos.

Dessa forma, este artigo indica novas pesquisas articulando comunidades de práticas e compartilhamento do conhecimento, bem como um estudo mais aprofundado sobre os aspectos informais da aprendizagem organizacional potencializados pelas comunidades de prática. 


\section{REFERÊNCIAS}

ANTONELLO, C. S.; GODOY, A. S. Aprendizagem organizacional no Brasil. Porto Alegre: Bookman, 2011.

CALDEIRA, Adilson; GODOY, Arilda Schmidt. Barreiras e incentivos à aprendizagem organizacional: um estudo de caso. REGE, São Paulo, Brasil, v. 18, n. 4, p. 513-530, out./dez. 2011.

DELORS, Jacques. Educação: um tesouro a descobrir (relatório para a UNESCO da Comissão Internacional sobre Educação para o Século XXI). Brasília: UNESCO, 2010.

DUARTE, Emeide Nóbrega at. al. Práxis de gestão do conhecimento no ambiente das organizações no escopo da ciência da informação. In: ENCONTRO NACIONAL DE PESQUISA EM CIÊNCIA DA INFORMAÇÃO, 16., 2015, J oão Pessoa. Anais... J oão Pessoa: ENANCIB, 2015.

FERNANDES, F. R.; CAPAVERDE, L. Z.; SILVA, H. F. N. Comunidades de prática: uma revisão bibliog ráfica sistemática sobre casos de aplicação organizacional. Atoz: novas práticas em informação e conhecimento, Curitiba, v. 5, n. 1, p. 44-52, 2016.

GIL, Antônio Carlos. Como elaborar projetos de pesquisa. São Paulo: Atlas, 2016.

KIMBLE, C.; HILDRETH, P. M. Communities of Practice: Going One Step Too Far? In: In: Association Information and Management (AIM), 9th, May 2004, Evry (France). Proceedings 9ème colloque de l'AIM. Evry: AIM, 2004. Disponível em <http://www.aim2004.int-evry.fr/pdf/Aim04_Kimble_Hildreth.pdf>. Acesso em 14 nov. 2017.

LÉVY, Pierre. 0 que é virtual? 2. ed. São Paulo: Editora 34, 2011.

MCKEEN, J . D.; SMITH, H. A. New Developments in Practice II: Enterprise Application Integration, Communications of the Association for Information Systems. v. 8, article 31, 2002.

NONAKA, Ikujiro.; TAKEUCHI, Hirokata. Gestão do conhecimento. Porto Alegre: Bookman, 2008.

PALLOFF, R. M.; PRATI. K. Construindo comunidades de aprendizagem no ciberespaço. Porto Alegre: Artmed, 2002.

RICHARDSON, Roberto J arry. Pesquisa social: métodos e técnicas. São Paulo: Atlas, 2014.

RODRIGUES, Rui Martinho. Pesquisa acadêmica: como facilitar o processo de preparação de suas etapas. São Paulo: Atlas, 2007.

SENGE, P. M. A quinta disciplina: arte e prática da organização de aprendizagem. 33. ed. São Paulo: Best Seller, 2017.

SILVA, Luan Carlos Santos et. al. Criação e gestão do conhecimento organizacional na estruturação dos nits no estado da Bahia: os desafios enfrentados pelas universidades estaduais. LAJ BM, v. 5, n. 1, p. 147-164, jan./jun. 2014.

WENGER, E. Communitiesofpracticeand social learning systems: thecareerof a concept. In: BLACKM ORE, C. (Ed.). Social learning systems andcommunitiesofpractice. London, UK: Springer, 2010. p.179-198.

WENGER, E.; LAVE, Jean. Cognition in practice: mind, mathematics and culture in everyday life. New York: Cambridge University Press, 1988.

WENGER, E.; MCDERMOTT, Richard.; SNYDER, William M. Cultivating communities of practice. Boston: Harvard Business School Press, 2002.

ZACCARELLI L. M.; GODOY, A. S. Perspectivas do uso diários nas pesquisas em organizações. Cadernos Ebape, v. 8, n. 3, p. 550-563, 2012. 